\title{
Boas práticas de maternança na perspectiva bioética: uma contribuição para a enfermagem pediátrica
}

\author{
Good motherhood practices from a bioethical perspective: a contribution to pediatric nursing \\ Buenas prácticas de maternidad en la perspectiva bioética: una contribución a la enfermería \\ pediátrica
}

Benedita Maria Rêgo Deusdará Rodrigues'; Patrícia Lima Pereira Peres ${ }^{\text {II }}$ S Sandra Teixeira de Araújo Pacheco ${ }^{\text {III }}$

\begin{abstract}
RESUMO: O estudo teve por objetivo promover a reflexão acerca das boas práticas de maternança no cotidiano dos profissionais que lidam diariamente com a mãe, o filho, incluindo o pai e, necessariamente, a família na ação de cuidar, com vistas ao seu conforto e bem-estar. Tema instigante que oportuniza desafios, quando nos referimos à atuação profissional que envolve o contexto das relações humanas cotidianas. O cuidar na sua realidade concreta, naquilo que é a sua característica essencial, um modo de ser humano que cuida e quer ser cuidado; portanto, numa perspectiva que envolve o caráter ético e bioético. Maternança, nesse sentido, compreende um cuidado humanizado que requer mais do que a ação sobre o outro, ou para o outro; respeita a autonomia dos sujeitos - cuidador, criança e sua família -, permitindo a todos os envolvidos que se coloquem na condição de agente, numa relação de reciprocidade.

Palavras-Chave: Ética; bioética; família; enfermagem neonatal/pediátrica.
\end{abstract}

ABSTRACT: This study aimed to encourage thinking about good motherhood practices in the day-to-day practice of professionals who deal daily with mothers and babies, including fathers and necessarily families in giving care, with a view to their comfort and well-being. This is an exciting subject that poses challenges, considering the professional activity involved in the context of everyday human relationships. This is the concrete reality of care, its essential characteristic as a way of being human that cares and wants to be cared for. Accordingly, it is an approach to care that involves the ethical and bioethical perspective. In this regard, motherhood comprises humanized care that requires more than acting on others or for others, but respects the autonomy of the subjects involved (caregiver, child and family), enabling all participants to position themselves as agents in reciprocal relationships. Keywords: Ethics; bioethics; family; neonatal/pediatric nursing.

RESUMEN: El objetivo del estudio fue promover la reflexión acerca de las buenas prácticas de maternidad en el cotidiano de los profesionales que se ocupan diariamente de la madre, del hijo, incluso del padre y, necesariamente, de la familia en la acción de cuidar, con vistas a su confort y bienestar. Tema instigador que plantea desafíos, cuando nos referimos a la actuación profesional que involucra el contexto de las relaciones humanas cotidianas. El cuidar en su realidad concreta, en aquello que es su característica esencial, un modo de ser humano que cuida y quiere ser cuidado; por lo tanto, en una perspectiva que involucra el carácter ético y bioético. Maternidad, en ese sentido, implica un cuidado humanizado que requiere algo más que la acción sobre el otro, o hacia el otro, respeta la autonomía de los individuos - cuidador, niño y su familia - permitiéndoles a todos los involucrados que se pongan en la condición de agente, en una relación de reciprocidad.

Palabras Clave: Ética; bioética; familia; enfermería neonatal/pediátrica.

\section{INTRODUÇÃO}

O cuidar na perspectiva das boas práticas de maternança inclui muito mais do que o aspecto biológico desse processo, transcende a sintomatologia dos problemas apresentados pela criança, englobando todo seu contexto familiar e social, pois cuida-se dessas pessoas, orientando-as e inserindo-as na própria ação de cuidar, visando ao seu conforto e bem-estar.
Desse modo, a pessoa passa a ser percebida como um ser humano singular, cujas necessidades individuais podem ser captadas pela linguagem, oral, corporal, escrita ou simbólica, pelos sentimentos e atitudes ${ }^{1}$.

Esse é um tema instigante que oportuniza desafios, pois ao mesmo tempo em que nos parece complexo, torna-se essencialmente simples, quando

IProfessora Titular do Departamento de Enfermagem Materno-Infantil da Faculdade de Enfermagem da Universidade do Estado do Rio de Janeiro. Brasil. E-mail: benedeusdara@gmail.com

IIProfessora Assistente do Departamento de Enfermagem Materno-Infantil da Faculdade de Enfermagem da Universidade do Estado do Rio de Janeiro. Brasil.E-mail: patricia.uerj@hotmail.com.

IIIProfessora Adjunta do Departamento de Enfermagem Materno-Infantil da Faculdade de Enfermagem da Universidade do Estado do Rio de Janeiro. Brasil. E-mail: stapacheco@yahoo.com.br. 
nos referimos à atuação profissional que envolve o contexto das relações humanas cotidianas. Este artigo de atualidade teve por objetivo promover a reflexão acerca das boas práticas de maternança no cotidiano dos profissionais que lidam diariamente com a mãe, o filho, incluindo o pai e, necessariamente, a família na ação de cuidar, com vistas ao seu conforto e bem-estar.

tema suscita profundas reflexões, afinal de quem estamos falando e para quem devemos nos dirigir. Falamos de uma mãe, do pai, do filho, do familiar cuidador? Inclui-se, aí, os diferentes profissionais que compõem a equipe multiprofissional. Nesse sentido, não se deve eximir do contexto da contemporaneidade, no qual se faz necessário um olhar mais abrangente para visualizar a maternança na perspectiva de quem, de fato, a realiza.

Entretanto, para que as transformações aconteçam no campo das práticas em saúde é necessária uma mudança de atitude profissional que se paute nas relações humanas. E, portanto, no processo de humanização do cuidar que tem como foco a pessoa.

O que se pretende é o respeito, a ética do respeito incondicional às pessoas. Compreender a pessoa como existência humana, como sujeito de direitos inalienáveis, em uma época em que a tecnociência é sempre mais autorreferente, técnica gera técnica com interferência humana cada vez menor²

Desse modo, há que se respeitar as relações que se estabelecem nas composições familiares atuais, diversas do núcleo tradicional, como, por exemplo, as relações homoafetivas, evitando as discriminações pautadas em valores pessoais, que, muitas vezes, se caracterizam pela intolerância e não possibilitam o cuidar na perspectiva humana.

Podemos, aqui, fazer algumas perguntas: De que, mesmo, estamos falando? E em quais concepções bioéticas queremos nos apoiar?

Estas indagações nos fazem lembrar Leonardo Boff ${ }^{3}$, em sua obra Saber cuidar: ética do humano compaixão pela terra, quando nos chama a atenção sobre o tamagochi e o cuidado. Destaca que a sociedade contemporânea, chamada sociedade do conhecimento e da comunicação, está criando, contraditoriamente, cada vez mais incomunicações e solidão entre as pessoas. Por exemplo, a internet pode conectar-nos com milhões de pessoas sem precisarmos sair de casa ou encontrar alguém. Através da internet, podemos conhecer o mundo, pagar contas, trabalhar e pedir várias coisas para atender às nossas necessidades e tudo isso sem falar com ninguém. Entretanto, tal feito nos traz algumas dificuldades, pois a relação com a realidade concreta, com seus cheiros, cores, frios, calores, pesos, resistências e contradições é mediada, muitas vezes, apenas pela imagem virtual.

Para ele, o mundo virtual criou um novo habitat para o ser humano, caracterizado pelo encapsulamento sobre si mesmo e pela falta do toque, do tato e do contato humano. Acrescenta que esta antirrealidade afeta a vida humana naquilo que ela possui de mais fundamental: o cuidado e a com-paixão. Cuidado é a essência humana. No cuidado, encontra-se o ethos fundamental do humano. Quer dizer, no cuidado, são identificados os princípios, os valores e as atitudes que fazem da vida um bem-viver e das ações um reto agir ${ }^{3}$.

E, nós, enfermeiros, profissionais da equipe de enfermagem, acadêmicos e os demais profissionais que integram a equipe multidisciplinar em saúde, podemos nos apoiar no pensamento de Boff ${ }^{3}$.

Nessa obra, ele chama atenção para o cuidado, que aparece em nossa sociedade como algo muito vulgar, quase ridículo, mas extremamente relevante: a exemplo do imprescindível zelar pelo tamagochi, pois sem cuidado, o brinquedo, um bichinho de estimação, poderia morrer. $\mathrm{O}$ cuidado por aquele bichinho denuncia a solidão em que vive o homem da sociedade da comunicação nascente.

Anuncia, também, que apesar da desumanização de grande parte da nossa cultura, a essência humana não se perdeu. Para ele, cuidar

[...] é mais que um ato; é uma atitude. [...] abrange mais que um momento de atenção, de zelo e de desvelo. Representa uma atitude de ocupação, preocupação, de responsabilização e de envolvimento afetivo com o outro ${ }^{3: 80}$.

\section{O Cuidado Ético e Bioético}

A partir do exposto, ressaltamos a necessidade de, cada vez mais, direcionar o cuidado para um fazer profissional que se pauta nas relações interpessoais, valorizando o contexto existencial. Para auxiliar a compreender esse fenômeno - o cuidar na sua realidade concreta, naquilo que é a sua característica essencial, é preciso conceber um modo de ser humano que cuida e quer ser cuidado, respeitando a dignidade, a liberdade, a autonomia e demais direitos de cidadania, portanto numa perspectiva que envolve o caráter ético e bioético.

Desse modo, esse é um tema de extrema importância para o agir do profissional da saúde, pois trabalhamos em prol do ser humano, que, do ponto de vista ontológico, portanto existencial, compreende uma dimensão concreta e singular de ser e estar no mundo. A existência é um modo de ser de cada um. Assim, precisamos lidar com este homem-sujeito das nossas ações profissionais, ao rigor do que a própria palavra nos impõe e, não menos que isso, com a mesma seriedade e criatividade.

Assim, ressaltamos que nós, os profissionais do humano, temos como matéria-prima para o exercício da profissão o próprio homem e toda a sua peculiaridade 
existencial, seja ela qual for. A preocupação central, nesse caso, é a disponibilidade para o outro, não buscando antever ou mesmo pré-conceituar as suas necessidades. Aqui se impõe a interação face a face, entre o enfermeiro e a pessoa que está sendo cuidada, na perspectiva de captar e planejar conjuntamente o que deverá ser feito para o seu bem. Aquilo que se expressa no cuidar, sem determinar a priori, sem marginalizar, viabilizando uma relação respeitosa e autônoma do outro que é incluído e interage para definir as suas melhores escolhas.

Cuidamos do outro, muitas vezes, sem qualquer reflexão sobre esse processo, preconcebendo suas possibilidades e limitações e agindo como se tudo soubesse. $\mathrm{O}$ que caracteriza uma grande contradição no cuidado que realizamos no dia a dia.

Esta contradição suscitada pelo tema nos é muito clara quando agimos por conveniências e obedecendo, sem qualquer avaliação crítica, a critérios preestabelecidos para todos, nos quais a rotina institucional se transforma, de modo geral, em determinações universais.

Nesse sentido, a Rede Cegonha ${ }^{4}$ propõe o seguinte conceito de atenção humanizada:

[...] envolve um conjunto de conhecimentos, práticas e atitudes que visam [...] garantir que a equipe de saúde realize procedimentos comprovadamente benéficos para a mulher e o bebê, que evite as intervenções desnecessárias e que preserve a privacidade e a autonomia desses sujeitos ${ }^{4: 9}$.

Dessa forma, o que se espera é limitar a ação do profissional sobre o outro no sentido de superioridade e de controle. Preservar a privacidade e autonomia é compreender que somos copartícipes no cuidado, que o corpo do outro não me pertence, suas escolhas, seus medos devem ser respeitados e, portanto, quando impomos nosso cuidado estamos, na verdade, descuidando. Essa perspectiva, que encontra respaldo na bioética, necessita ser incorporada não apenas pela Rede Cegonha ${ }^{4}$, como uma política pública, mas por todo o agir (ético?) do profissional.

Vale, aqui, destacar que:

A bioética é um neologismo derivado das palavras gregas bios (vida) e ethike (ética). Pode-se defini-la como sendo o estudo sistemático das dimensões morais - incluindo visão, decisão, conduta e normas morais - das ciências da vida e da saúde, utilizando uma variedade de metodologias éticas num contexto interdisciplinar ${ }^{5: 319}$.

Portanto, pautando-se no principialismo ou bioética dos princípios ${ }^{6}$, torna-se importante ressaltar que a autonomia é uma palavra derivada do grego autos (que quer dizer próprio) e nomos (ou regra, governo ou lei), autogoverno, direitos de liberdade, privacidade, escolha individual, liberdade da vontade, ser o motor do próprio comportamento e pertencer a si mesmo. Deve-se assinalar que praticamente todas as teorias da autonomia consideram duas condições essenciais: a liberdade - independência de influências controladoras - e qualidade do agente moral, capacidade de agir intencionalmente. Violar a autonomia de uma pessoa é tratá-la meramente como um meio, de acordo com os objetivos de outros, sem levar em conta os objetivos da própria pessoa. Pessoas autônomas são fins em si mesmas, capazes de determinar o próprio destino ${ }^{6}$.

Ainda, o princípio da beneficência refere-se à ação realizada em benefício de outros. É a obrigação moral de agir buscando o bem. Muitos atos de beneficência não são obrigatórios, mas qualquer princípio de beneficência expressa a obrigação de ajudar as outras pessoas, promovendo seus interesses legítimos e direitos inalienáveis ${ }^{6}$.

\section{A Perspectiva da Humanização em SAÚde}

É preciso destacar que humanização é um processo que confirma no homem alguns traços essenciais, como o exercício da reflexão, a aquisição do saber, a disposição para a compreensão do outro, o refinamento da sensibilidade, a capacidade de apreender e contextualizar os problemas da vida, a percepção da complexidade do mundo e dos seres, o senso de humor e a capacidade de adequar o conhecimento a diferentes realidades socioculturais, respeitando os direitos humanos?

Para dar ênfase ao contexto destas reflexões:

[...] cuidar de outra pessoa, no sentido mais significativo, é ajudá-la a crescer e a se realizar. $\mathrm{O}$ cuidado, quando ajuda o outro a crescer e se realizar, é um processo, uma maneira de se relacionar com alguém, que implica desenvolvimento, da mesma forma que a amizade só pode emergir com o tempo, através da confiança mútua, e de um aprofundamento e uma transformação qualitativa do relacionamento ${ }^{8: 24}$

$\mathrm{Na}$ medida em que se cuida, ajudando o outro a crescer e se realizar, proporcionamos a ele algumas características essenciais que permitem o seu desenvolvimento, bem como a sua capacidade para exercer a autonomia.

Assim, participar representa uma ação dos sujeitos envolvidos numa dada situação de cuidado e não, apenas, um discurso inovador. Eis aí um dos principais desafios da bioética: tratar os sujeitos (competentes) em situação de igualdade, respeitando sua dignidade.

Portanto, as bases elementares e fundamentais da ética são a própria existência e experiência do ser que é capaz de pensar e de se orientar para viver segundo seu modo de existir, que é um modo consciente e refletido. Cada um vive e convive revelando seu próprio modo de ser no mundo, carregado de sua 
própria situação biográfica, contextualizada pelas oportunidades e escolhas existenciais.

Dessa forma, para cuidar de alguém, torna-se necessário conhecer quem é este alguém, quais os seus potenciais e limitações, e o que conduz o seu crescimento; saber como responder às suas necessidades, que são, muitas vezes, reflexos dos próprios poderes e limitações do profissional. Não se conhece antecipadamente o outro, prevendo seus limites para agir.

Cuidar envolve dedicação, paciência, sinceridade, confiança, humildade, esperança, coragem. Estas características são indispensáveis para um cuidar humano.

O cuidado humano e cuidar são vistos como o ideal moral da enfermagem, isto é, um estilo, um modo próprio de cuidar, no qual o enfermeiro é coparticipante, num processo de interação que se concretiza na intersubjetividade ${ }^{9}$. O cuidado entendido como uma interação entre dois ou mais sujeitos visa ao alívio de um sofrimento ou ao alcance de seu bem-estar ${ }^{10}$.

Nesse contexto, a bioética não se utiliza simplesmente dos conhecimentos de outras ciências, mas cria um espaço de diálogo interdisciplinar, ou seja, de colaboração e interação de diferentes áreas de conhecimento. Nessa perspectiva, as decisões não podem ser tomadas baseando-se, apenas, nos fatos do cotidiano que surgem no campo das práticas em saúde. Isto pode conduzir ao erro, pois é preciso levar em conta a singularidade das pessoas envolvidas na ação de cuidar.

A bioética, considerada uma ética aplicada aos comportamentos de agentes morais que influem na qualidade de vida de outros seres vivos, tem, reconhecidamente, uma dupla tarefa: a de descrever e compreender os conflitos de interesses e de valores entre agentes e pacientes morais e a de prescrever os comportamentos corretos à luz de alguma teoria moral ${ }^{11}$.

A bioética nos oferece a possibilidade de repensar o fazer em enfermagem de forma mais humana e compartilhada, na qual todos os envolvidos sejam sujeitos ativos do processo ${ }^{12}$.

Desse modo, o diálogo estabelecido entre o profissional e a pessoa e/ou a família constitui-se no principal instrumento para a relação intersubjetiva que permeia o cuidar individual e, portanto, mais adequado naquele momento. Para tanto, o trabalho interdisciplinar, apoiado no projeto intersubjetivo de ação, do qual a pessoa é parte integrante, é imprescindível para a tomada de decisões. Assim, o olhar múltiplo e cauteloso é indispensável, pois o individual, ou seja, centrado em um único profissional, não dará conta dessa realidade.

A ética não é inventada por um sábio ou um santo: ela se origina na relação viva entre um eu e um tu ou entre duas pessoas ${ }^{13}$. Portanto, a ética é relacional. Surge no convívio das pessoas e das comunidades. A reciprocidade interpessoal estabelece a eticidade de nossos comportamentos e ações.
Considerando a maternança e a bioética, é preciso repensar o cuidado, o qual requer mais do que a ação sobre o outro ou para o outro. É um cuidado que, respeitando a autonomia dos sujeitos, cuidador, criança e família, permite a todos os envolvidos que se coloquem na condição de agente, numa relação de reciprocidade.

Esta relação está para além da discussão acerca da questão legal da criança como incapaz e, portanto, não autônoma. Aqui, sinalizamos a autonomia como característica do humano. Nessa perspectiva, mesmo diante de um neonato ou lactente, devo olhá-lo como um ser autônomo, livre, racional em potencial, pois o homem é sempre um vir a ser e, portanto, deve ser respeitado como tal.

Entretanto, nossa sociedade ainda tem dificuldades em dar voz à criança, em entendê-la como sujeito com direitos, reflexo da construção histórica da infância no Brasil. Dessa maneira, a maternança ainda é algo a ser construído, assimilado.

Ainda, nossas atitudes, escolhas e práticas estão relacionadas à nossa posicionalidade. Perspectivas posicionais enraizadas em práticas assimétricas de cuidado, em particular aquele que envolve a criança e a família, necessitam ser removidas, dando lugar às práticas entre humanos, isto é, entre iguais ${ }^{14}$.

\section{Considerações Finais}

O cuidar, na perspectiva das boas práticas de maternança e bioética, indica uma atuação profissional humanizada, sem determinar a priori, sem marginalizar e, sobretudo, na perspectiva de uma relação respeitosa e autônoma do outro que é incluído no processo e interage para definir as suas melhores escolhas. Entretanto, nossa sociedade ainda tem dificuldades em dar voz à criança, em entendê-la como sujeito de direitos, reflexo da construção histórica da infância no Brasil e, portanto, a maternança ainda é algo a ser construído, assimilado. Esta relação está para além da discussão acerca da questão legal da criança como incapaz e, consequentemente, sem autonomia. Nessa perspectiva, mesmo diante de um neonato ou lactente, devo olhá-lo como um ser autônomo, livre, racional em potencial e, nesse sentido, o homem é sempre um vir a ser que deve ser respeitado como tal.

\section{REFERÊNCIAS}

1.Pegoraro O, Rodrigues BMRD, Nunes MGS. Bioética em feridas. In: Blanck M; Giannini T, organizadoras. Úlceras e feridas: as feridas têm alma. Rio de Janeiro: Di Livros Editora LTDA; 2014. p. 5-15.

2.Pegoraro O, Rodrigues BMRD, Nunes MGS. Bioética em feridas. In: Blanck M; Giannini T, organizadoras. Úlceras e feridas: as feridas têm alma. Rio de Janeiro: Di Livros Editora LTDA; 2014. p. 5-15.

3.Boff L. Saber cuidar: ética do humano, compaixão pela terra. $7^{\mathrm{a}}$ ed. Rio de Janeiro: Vozes; 2001. 
4.Ministério da Saúde (Br). Manual prático para a implementação da Rede Cegonha. 2011 [citado em 09 nov 2014] Disponível em manual-pratico-redecegonha-[444-090312-SES-MT]\%20(3).pdf

5.Reich WT. Encyclopedia of Bioethics. The word bioethics: its birth and the legacies of those who shaped it, in Kennedy Instiute of Ethics Journal, 1994; 4:319-35. 6.Beauchamp TL, Childress JF. Princípios de Ética Biomédica. Tradução de Luciana Pudenzi. São Paulo: Edições Loyola; 2002.

7.Cândido A. Vários escritos. São Paulo: Duas Cidades; 1995. 8.Mayeroff M. A arte de servir ao próximo para servir a si mesmo. Rio de Janeiro: Editora Record; 1971.

9. Waldow VR, Borges RF. Cuidar e humanizar: relações e significados. Acta Paul Enferm 2011; 24:414-8.
10.Costa VGS, Rodrigues BMRD, Pacheco STA. As relações interpessoais no cuidar do cliente em espaço Onco-hematológico: uma contribuição do enfermeiro. Rev enferm UERJ. 2012; 20:209-14.

11.Schramm FR. Existem boas razões para se temer a biotecnociência? Revista BIOETHIKOS. 2010;4:189-97. 12.Rodrigues BMRD, Santana JS de, Pacheco STA, Ciuffo LL, Gomes APR Rosa JS Cardoso JMRM. A ética no cuidar em enfermagem: contribuições da fenomenologia sociológica de Alfred Schütz. Rev enferm UERJ. 2011; 19:236-41.

13.Pegoraro O. Introdução à ética contemporânea. Rio de Janeiro: Uapê; 2005.

14.Sen A. A ideia de justiça. São Paulo: Companhia das Letras; 2011. 